\title{
Deamidation and glycation of a Bacillus licheniformis -amylase during industrial fermentation can improve detergent wash performance
}

\author{
Pontoppidan, Connie; Kaasgaard, Svend G.; Sønksen, Carsten P.; Andersen, Carsten; Svensson, Birte
}

Published in:

Amylase

Link to article, DOI:

10.1515/amylase-2021-0004

Publication date:

2021

Document Version

Publisher's PDF, also known as Version of record

Link back to DTU Orbit

Citation (APA):

Pontoppidan, C., Kaasgaard, S. G., Sønksen, C. P., Andersen, C., \& Svensson, B. (2021). Deamidation and glycation of a Bacillus licheniformis -amylase during industrial fermentation can improve detergent wash performance. Amylase, 5(1), 38-49. https://doi.org/10.1515/amylase-2021-0004

\section{General rights}

Copyright and moral rights for the publications made accessible in the public portal are retained by the authors and/or other copyright owners and it is a condition of accessing publications that users recognise and abide by the legal requirements associated with these rights.

- Users may download and print one copy of any publication from the public portal for the purpose of private study or research.

- You may not further distribute the material or use it for any profit-making activity or commercial gain

- You may freely distribute the URL identifying the publication in the public portal 


\section{Research Article}

Connie Pontoppidan, Svend G. Kaasgaard, Carsten P. Sønksen, Carsten Andersen*, Birte Svensson*

Deamidation and glycation of a Bacillus licheniformis $\alpha$-amylase during industrial fermentation can improve detergent wash performance

https://doi.org/10.1515/amylase-2021-0004

Received April 12, 2021; accepted June 3, 2021.

\begin{abstract}
The industrial thermostable Bacillus licheniformis $\alpha$-amylase (BLA) has wide applications, including in household detergents, and efforts to improve its performance are continuously ongoing. BLA during the industrial production is deamidated and glycated resulting in multiple forms with different isoelectric points. Forty modified positions were identified by tandem mass spectrometric peptide mapping of BLA forms separated by isoelectric focusing. These modified 12 asparagine, 9 glutamine, 8 arginine and 11 lysine residues are mostly situated on the enzyme surface and several belong to regions involved in stability, activity and carbohydrate binding. Eight residues presumed to interact with starch at the active site and surface binding sites (SBSs) were subjected to mutational analysis. Five mutants mimicking deamidation $(\mathrm{N} \rightarrow \mathrm{D}, \mathrm{Q} \rightarrow \mathrm{E})$ at the substrate binding cleft showed moderate to no effect on thermostability and $k_{\text {cat }}$ and $K_{\mathrm{M}}$ for maltoheptaose and amylose. Notably, the mutations improved laundry wash efficiency in detergents at $\mathrm{pH} 8.5$ and 10.0. Replacing three reducing sugar reactive side chains $(\mathrm{K} \rightarrow \mathrm{M}, \mathrm{R} \rightarrow \mathrm{L})$ at a distant substrate binding region and two SBSs enhanced wash performance especially in liquid detergent at $\mathrm{pH} 8.5$, slightly improved
\end{abstract}

\footnotetext{
*Corresponding authors: Birte Svensson, Enzyme and Protein Chemistry, Department of Biotechnology and Biomedicine, Technical University of Denmark, Søltofts Plads, building 224, DK-2800, Kgs. Lyngby, Denmark, E-mail: bis@bio.dtu.dk; Carsten Andersen, Novozymes A/S, Biologiens Vej 2, DK-2800, Kgs. Lyngby, Denmark, E-mail: cara@novozymes.com

Connie Pontoppidan, Enzyme and Protein Chemistry, Department of Biotechnology and Biomedicine, Technical University of Denmark, Søltofts Plads, building 224, DK-2800, Kgs. Lyngby, Denmark; Ascendis Pharma A/S, Tuborg Boulevard 12, DK-2900 Hellerup, Denmark Svend G. Kaasgaard, Connie Pontoppidan, Carsten P. Sønksen, Carsten P. Sønksen, Novo Nordisk A/S, Novo Alle 1, DK-2880 Bagsvaerd, Denmark
}

enzymatic activity and maintained thermostability. Wash performance was most improved (5-fold) for the N265D mutant near substrate binding subsite +3 .

Keywords: mass spectrometric peptide mapping; site-directed mutagenesis; surface binding sites; thermostability; enzyme kinetics.

\section{Abbreviations}

AGC, automated gain control; AGE, advanced glycation end-product; BHA, Bacillus halmapalus $\alpha$-amylase; BLA, Bacillus licheniformis $\alpha$-amylase; DSC differential scanning calorimetry; ETD, electron transfer dissociation; GH, glycoside hydrolase; HCD, high-energy C-trap dissociation; IEF, isoelectric focusing; MG-HI, methylglyoxal-derived hydroimidazolone; SBS, surface binding site.

\section{Introduction}

$\alpha$-Amylase (E.C. 3.2.1.1., 1,4- $\alpha$-D-glucan glucanohydrolase) catalyses hydrolysis of $\alpha$-D-(1,4) glucosidic linkages in starch and related oligo- and polysaccharides, releasing maltooligosaccharides, maltose and glucose [1-3]. Most $\alpha$-amylases belong to the very large glycoside hydrolase family 13 (GH13) of the CAZy database ([4]; http://www. cazy.org/). Several $\alpha$-amylases important for starch liquefaction and saccharification in starch and fuel alcohol industries, stain removal in household detergents, and in baking and brewing belong to the subfamily GH13_5 of bacterial $\alpha$-amylases [5-8]. Its stability at alkaline $\mathrm{pH}$ and elevated temperature makes Bacillus licheniformis $\alpha$-amylase (BLA) particularly suitable for application in laundry detergents, where $\alpha$-amylases constitute the second most used enzyme group after proteases [6,7,9]. 
Crystal structures are available for a number of industrially important $\alpha$-amylases, including BLA [1]. It contains three domains (A, B and C) similarly to most of the GH13 $\alpha$-amylases. The active site is situated on the $(\beta / \alpha)_{8}$-barrel domain $A$, and the loop domain $B$, that is inserted between $\beta$-strand 3 and $\alpha$-helix 3 , also participates in substrate binding. By contrast, the domain $\mathrm{C}$, which has an anti-parallel $\beta$-sheet structure is rarely involved in function, but required for the overall structural integrity of the enzyme [3]. BLA has in addition to the catalytic site nucleophile (D231), acid/base (E261) and a third acid residue (D328), involved in stabilizing substrate reaction intermediates at binding subsite -1 [10], five substrateaccommodating glycon-binding subsites $(-1$ through -5$)$ and three aglycon-binding subsites $(+1$ through +3$)[1,11]$ formed by domains A and B. A unique linearly arranged $\mathrm{Ca}^{2+}-\mathrm{Na}^{+}-\mathrm{Ca}^{2+}$ ion triad at the interface of domains $\mathrm{A}$ and $B$ is characteristic of $\alpha$-amylases in subfamily GH13_5 $[1,10,12]$. This triad stabilizes the structure around the active site and is important for the thermostability $[11,13]$. Similar to the related Bacillus halmapalus $\alpha$-amylase (BHA) [14], domains A and C of BLA contain so-called surface binding sites (SBSs) or secondary carbohydrate binding sites, which are non-catalytic, but functionally important and situated at a certain distance from the active site. SBSs are particularly prominent in GH13, but have been reported in about 25 other GH and glycosyl transferase (GT) families [15-18]. SBSs typically contain aromatic residues engaged in the carbohydrate binding and can cooperate with the active site, for example, by anchoring polysaccharides undergoing processive degradation, serving as point of attachment onto starch granules and soluble polysaccharides or be involved in allosteric regulation of activity [15-18].

Industrial-scale production of $\alpha$-amylases by heterologous expression in bacterial or fungal hosts has been found to result in modifications of protein side chains, typically deamidation, glycation and oxidation that can alter enzyme stability and activity $[19,20]$. Glycation involves reactions between lysine and arginine side chains and reducing sugars resulting in formation of ketoamines, which can rearrange to more reactive carbonyl compounds termed advanced glycation endproducts (AGEs) [21,22]. Commonly reported AGEs include 3-deoxyglucosone, carboxymethyl, carboxyethyl, and methylglyoxal-derived hydroimidazolone (MG-HI) [23-26]. Industrial BLA as a consequence encompasses multiple protein forms presenting a $\mathrm{pI}$ range due to deamidation of asparagine and glutamine residues and glycation of lysine and arginine residues, which can be identified by mass spectrometry. The functional impact of these chemical modifications of amino acid side chains is here assessed by mutational analysis in BLA, involving eight modified residues selected in binding regions including substrate aglycon and glycon interacting subsites at the active site and two SBSs, respectively. Remarkably, most of these BLA mutants acquired improved laundry wash performance.

\section{Materials and methods}

\subsection{Bacillus licheniformis $\alpha$-amylase (BLA)}

Industrial BLA was produced recombinantly in Bacillus licheniformis and kindly provided by Novozymes A/S.

\subsection{Production of BLA wild-type and mutant}

BLA mutants were prepared by Novozymes A/S using sitedirected mutagenesis according to described principles [27]. Wild-type and BLA mutant proteins were produced recombinantly with $B$. subtilis as host by fermentation at $37^{\circ} \mathrm{C}$ for $96 \mathrm{~h}$ in a medium consisting of $100 \mathrm{~g} / \mathrm{L}$ sucrose, $40 \mathrm{~g} / \mathrm{L}$ soybean meal, $10 \mathrm{~g} / \mathrm{mL} \mathrm{Na}_{2} \mathrm{HPO}_{4} \cdot 12 \mathrm{H}_{2} \mathrm{O}, 0.01 \%$ (v/v) Dowfax (Dow Chemicals) $63 \mathrm{~N} 10$ and $5 \mathrm{~g} / \mathrm{L} \mathrm{CaCO}_{3}$.

\subsection{Enzyme purification}

Cultures (typically $100 \mathrm{~mL}$ ) containing secreted BLA wild-type and mutants were centrifuged $(5,400 \times g, 50$ $\mathrm{min})$. The supernatants were filtered $(0.2 \mu \mathrm{m}$ PES filters), added MOPS, $\mathrm{CaCl}_{2}$ and $\left(\mathrm{NH}_{4}\right)_{2} \mathrm{SO}_{4}$ to $20 \mathrm{mM}, 1 \mathrm{mM}$ and 1 $\mathrm{M}$, respectively, and adjusted to $\mathrm{pH}$ 7.5. BLA proteins were purified by hydrophobic interaction chromatography (Phenyl Sepharose 6 Fast Flow packed in a 50 mL XK 26/20 column; GE Healthcare) pre-equilibrated in the above buffer, washed with two column volumes of buffer and eluted by a linear $\left(\mathrm{NH}_{4}\right)_{2} \mathrm{SO}_{4}$ gradient (1-0 M) in the buffer. Amylase containing fractions were identified by using SDS-PAGE (NuPAGE 4-12\% Bis-Tris gradient gel; Invitrogen) and enzyme activity analysis spectrophotometrically at $510 \mathrm{~nm}$ as described by the manufacturer (Amylazyme $\alpha$-amylase assay; Megazyme). One Amylazyme tablet was suspended in $5 \mathrm{~mL} 25 \mathrm{mM}$ HEPES, $1 \mathrm{mM} \mathrm{CaCl}$, $\mathrm{pH} 7.5$ and $575 \mu \mathrm{L}$ hereof was incubated $15 \mathrm{~min}$ at room temperature with $20 \mu \mathrm{L}$ enzyme. Fractions containing activity were pooled, dialysed $\mathrm{O} / \mathrm{N}$ against $10 \mathrm{mM}$ Tris, 1 $\mathrm{mM} \mathrm{CaCl}, \mathrm{pH} 8.9$, and further purified by anion exchange 
chromatography (50 mL Source 30Q packed in a XK26/20 column; GE Healthcare), washed with one column volume of buffer and eluted by a linear $\mathrm{NaCl}$ gradient $(0-600 \mathrm{mM})$ in $20 \mathrm{mM}$ Tris, $1 \mathrm{mM} \mathrm{CaCl}_{2}$, pH 8.9 over $110 \mathrm{~min}$ at a flow rate of $8 \mathrm{~mL} / \mathrm{min}$. Fractions containing only BLA (verified by SDS-PAGE) were pooled, concentrated and bufferexchanged to $20 \mathrm{mM}$ HEPES, $1 \mathrm{mM} \mathrm{CaCl}$, $\mathrm{pH} 7.0$ (Vivaspin 20 10,000 MWCO PES spin columns; Sartorius) and stored frozen until use. Protein concentrations were determined by amino acid analysis $[28,29]$.

\subsection{Isoelectric focusing (IEF)}

BLA samples were buffer-exchanged to 25 mM HEPES, 1 $\mathrm{mM} \mathrm{mM} \mathrm{CaCl}{ }_{2}, \mathrm{pH} 7.5$ and desalted (Centrifugal devices; Nanosep $10 \mathrm{~K}$ Omega, PALL life science) prior to IEF (FocusGel 3-7 with an Amersham Isoelectric Focusing Calibration Kit low range $\mathrm{pH}$ 2.5-6.5, GE Healthcare). IEF was run according to the manufacturer's protocol loading $60 \mu \mathrm{g}$ protein samples. Gels were stained with Coomassie blue.

\subsection{In-gel digestion in $\mathrm{H}_{2}{ }^{18} \mathrm{O}$}

IEF protein bands were cut out, destained twice in 50\% ethanol, dehydrated in 100\% acetonitrile (15 min) and the gel fragments were dried in Speedvac $\left(1 \mathrm{~h}, 50^{\circ} \mathrm{C}\right)$. The following solutions were made with $\mathrm{H}_{2}{ }^{18} \mathrm{O}\left(97\right.$ atom $\%{ }^{18} \mathrm{O}$; Sigma-Aldrich) to distinguish deamidations present in purified BLA forms from those occurring during proteolysis $[30,31]$. The dried gel fragments were incubated in $15 \mu \mathrm{L}$ of $27 \mathrm{ng} / \mu \mathrm{L}$ trypsin or $2.7 \mathrm{ng} / \mu \mathrm{L}$ Asp-N (both sequencing grade, Roche Diagnostics) in $50 \mathrm{mM} \mathrm{NH}_{4} \mathrm{HCO}_{3}$ for $45 \mathrm{~min}$ at $5^{\circ} \mathrm{C}$. After proteolysis the remaining protease solution was removed, and the gel samples were further incubated at 37 ${ }^{\circ} \mathrm{C} \mathrm{O} / \mathrm{N}$ in the presence of $50 \mu \mathrm{L} 50 \mathrm{mM} \mathrm{NH}_{4} \mathrm{HCO}_{3}$. Peptides were extracted from gel pieces with $70 \%$ acetonitrile, $0.1 \%$ trifluoroacetic acid (thrice), dried in Speedvac $\left(1 \mathrm{~h}, 50^{\circ} \mathrm{C}\right)$ and redissolved in $80 \mu \mathrm{L} 5 \%$ formic acid for MS analysis.

\subsection{Tandem mass spectrometry}

LC-MS/MS was performed with higher energy C-trap Dissociation (HCD) (LTQ Orbitrap Velos; Thermo Scientific) or electron transfer dissociation (ETD) fragmentation (LTQ Orbitrap XL; Thermo Scientific). ETD leaves labile modifications intact facilitating identification of glycations. Both instruments were equipped with a nano-
ESI source (Nanospray Flexion Source, Thermo Scientific) coupled to an EASY-nLC II (Thermo Scientific). Peptides were separated on Thermo Scientific EASY-Column (C18) $2 \mathrm{~cm} \times 100 \mu \mathrm{m}$ i.d. followed by a Thermo Scientific EASYColumn (C18) $10 \mathrm{~cm} \times 75 \mu \mathrm{m}$ i.d., eluting with a $5-50 \%$ acetonitrile gradient in $0.1 \%$ formic acid over $60 \mathrm{~min}$ at a flow rate of $250 \mathrm{~nL} / \mathrm{min}$.

Orbitrap Velos was run with automatic gain control (AGC) target of 1,000,000 with 30,000 resolution and 10 ms maximum ion injection time in full MS. For MS/MS the AGC target was 50,000 with $100 \mathrm{~ms}$ injection time and resolution of 7,500. The HCD normalized collision energy was $40 \%$ and the 10 most intense precursor ions in the range 350-1750 m/z were selected for MS/MS. Orbitrap XL $M^{1}$ was performed with a resolution of $60,000($ at $400 \mathrm{~m} / \mathrm{z}$ ). AGC target was 500,000 with maximum ion injection time $300 \mathrm{~ms}$ for the orbitrap in full MS. MS/MS was performed in the ion trap with AGC target of 40,000. ETD reactions were performed for $85 \mathrm{~ms}$ detecting fragment ions in the ion trap with 200 ms maximum injection time using 3 microscans selecting the four most abundant precursor ions in the range $350-1200 \mathrm{~m} / \mathrm{z}$, rejecting charge state 1 and 2. Data analysis was performed with Mascot (Matrix Science). Searches were conducted against a custommade database containing 14,100 sequences with decoy option enabled with trypsin or Asp-N as enzyme allowing 5 missed cleavages with $10 \mathrm{ppm}$ precursor mass tolerance, 0.5 Da fragments mass tolerance for ETD and 0.02 Da mass tolerance for HCD. The following variable modifications were chosen: Deamidated (NQ), Deamidated ${ }^{18} \mathrm{O}(1)(\mathrm{NQ})$, Label ${ }^{18} \mathrm{O}(1)\left(\mathrm{C}\right.$-term), Label ${ }^{18} \mathrm{O}(2)(\mathrm{C}$-term), Hex (KR), 3-deoxyglucosone (KR), Carboxymethyl(KR), Carboxyethyl (KR), MG-HI (methylglyoxal-derived hydroimidazolone; KR), Oxidation (M), Carbamyl (KR), Acetyl (K).

\subsection{Differential scanning calorimetry}

Unfolding of BLA proteins (approx. $1 \mathrm{mg} / \mathrm{mL}$ in $25 \mathrm{mM}$ HEPES, $1 \mathrm{mM} \mathrm{CaCl}$, pH 7.0) was analysed by differential scanning calorimetry (DSC) (Microcal VP-capillary DSC; GE Healthcare) at a scan rate of $1.5^{\circ} \mathrm{C} / \mathrm{min}$ to a final temperature of $130{ }^{\circ} \mathrm{C}$. $\mathrm{T}_{\max }$ is the temperature at the peak maximum of the transition from folded to unfolded state. Data analysis was performed using the Origin software package (MicroCal; GE Healthcare). 


\section{$2.8 \alpha$-Amylase activity assays}

\subsubsection{Maltoheptaose}

The kit AMYL $\alpha$-amylase liquid (Roche) containing a modified maltoheptaose substrate solution [4,6-ethylidene-(G7)-pNP] and an $\alpha$-glucosidase solution was used to determine initial rates of hydrolysis at 11 substrate concentrations (0.025-3 mM) in 52.5 mM HEPES $\mathrm{pH}$ 7.0. The assay was run on a KONELAB ARENA 30 (Thermo Electron Corporation) at $30{ }^{\circ} \mathrm{C}$ mixing $147 \mu \mathrm{L}$ $\alpha$-glucosidase with $83 \mu \mathrm{L}$ substrate and adding $20 \mu \mathrm{L}$ enzyme (3-15 nM in the above buffer). After 3 min preincubation, colour formation was measured 7 times over $2 \mathrm{~min}$ at $405 \mathrm{~nm}$ and quantified using 0-0.6 mM $p$-nitrophenol (Sigma). $K_{\mathrm{M}}$ and $k_{\text {cat }}$ were obtained by fitting of the Michaelis-Menten equation (CurveExpert 1.3; http:// www.curveexpert.net/).

\subsubsection{Amylose DP440}

Amylase (3-5 nM, $110 \mu \mathrm{L}$ in $20 \mathrm{mM}$ HEPES, $5 \mathrm{mM} \mathrm{CaCl}_{2}$, $\mathrm{pH}$ 7.0, 0.005\% w/v bovine serum albumin) was added to amylose DP440 (Amylose type III from potato; Sigma) at 10 different concentrations $(0.1-2.5 \mathrm{mg} / \mathrm{mL}, 990 \mu \mathrm{L})$ in $20 \mathrm{mM}$ HEPES pH 7.0, $5 \mathrm{mM} \mathrm{CaCl}$, 4.44\% v/v dimethyl sulfoxide, $0.005 \% \mathrm{w} / \mathrm{v}$ bovine serum albumin. Aliquots $(200 \mu \mathrm{L})$ were removed at $2.5 \mathrm{~min}$ intervals and initial rates of reducing power formation were determined at $30{ }^{\circ} \mathrm{C}$ using copper-bicinchoninate with maltose as standard and measuring colour formation spectrophotometrically at $540 \mathrm{~nm}[32,33] . K_{\mathrm{M}}$ and $k_{\text {cat }}$ were obtained as described above.

\subsection{Wash performance assay}

Wash performance was determined on coloured rice starch cotton textile, CS-28 (Center For Testmaterials BV), using a mini wash robot (Novozymes). CS-28 strips were mounted on racks, which moved up and down into wash beakers (50 times/min) during washing performed at 40 ${ }^{\circ} \mathrm{C}$ for $30 \mathrm{~min}$ at six enzyme concentrations (0-1.0 mg /L) using either a liquid detergent $(\mathrm{pH} 8.5)$ or a powder detergent ( $\mathrm{pH}$ 10.0) followed by 5 min rinse in cold water.

The liquid detergent ( $0.8 \mathrm{~g} / \mathrm{L}$ during the wash) was composed of $20 \%$ linear alkylbenzene sulphonate (Nacconol 90G), 10\% alkyl ether sulphate (STEOL CS-370E), 10\% alcohol ethoxylate (AEO, Bio-soft N25-7, Stepan Company), 4\% oleic acid, 0.5\% ethanol, 1.5\% sodium xylene sulfonate, 7\% 1,2-propanediol, 8\% tri-Nacitrate, $0.5 \%$ triethanolamine, $1.5 \%$ boric acid, $\mathrm{pH}$ 8.5. The powder detergent wash system contained $0.035 \mathrm{~g} / \mathrm{L}$ AEO with $1.715 \mathrm{~g} / \mathrm{L}$ powder detergent composed of $17 \%$ linear alkylbenzene sulphonate, 20\% sodium carbonate, $12 \%$ sodium disilicate, 15\% Zeolite A, 1\% Sokalan CP5 (maleic acid/acrylic acid co-polymer), 34\% sodium sulphate. Both detergent mixtures were prepared with water hardness of $15^{\circ} \mathrm{dH}(\mathrm{Ca} / \mathrm{Mg}$ 4:1). All percentages are in w/w. After wash, rinse and drying, the colour remission of the CS-28 strips was measured at 460 $\mathrm{nm}$ (TIDAS; Zeiss spectrophotometer). Wash efficiency was given in delta remission units, i.e. the difference between the absorbance of the remission of a blank control (cotton patch washed in detergent without enzyme) and the enzyme sample. The higher the delta remission value the better was the wash performance of the enzyme.

\section{Results}

\subsection{Identification of BLA modifications by LC-MS/MS}

Industrial BLA contained different forms of varying $\mathrm{pI}$ in the range $\mathrm{pH}$ 5.4-6.9, the most prominent component on the IEF gel having pI 6.7 (Fig. 1). Protein extracted from twelve bands was subjected to in-gel digestion with trypsin or Asp-N and the modified amino acid residues were identified in eleven of these bands by peptide mapping using LC-MS/MS. The predominant side chain modifications were deamidation and glycation identified for a total of 40 BLA residues (Table 1) together with oxidation of 6 methionine residues (not shown). From 2 to 16 modified positions were identified from the individual bands on the IEF gel. It is anticipated that protein forms contain more than a single chemical modification as supported by 21 of the 40 modified residues being identified in more than one of the 11 protein bands. Notably six bands contained modified R242, N27 and R437, while modified K237, N265 and N326 were found in 5 bands (Table 1). Overall, these identified modified positions comprised 21 deamidations $(12 \mathrm{~N} \rightarrow \mathrm{D}$ and $9 \mathrm{Q} \rightarrow \mathrm{E}$ of a total of $45 \mathrm{~N}$ and $\mathrm{Q}$ residues in BLA), and 19 glycations ( 8 of $\mathrm{R}$ and 11 of $\mathrm{K}$ of a total of $49 \mathrm{R}$ and $\mathrm{K}$ residues in BLA) presenting different AGEs; i.e. 3-deoxyglucosone, carboxymethyl, carboxyethyl and MG-HI (Table 1). Deamidation and glycation occurred mostly on the BLA surface although a few deamidations took place in a buried region near the active site. Several regions involved in BLA stability, activity and substrate 
Table 1: Chemical modifications identified from 11 bands of BLA in IEF (Fig. 1) by LC-MS/MS fragmenting with HCD and ETD. ${ }^{a}$

\begin{tabular}{|c|c|c|c|}
\hline Site & Modification & ID in band & Covered \\
\hline Q9 & Dea & 1 & + \\
\hline R23 & $\mathrm{Cbm} / \mathrm{Cbe}$ & 1,7 & + \\
\hline R24 & MG-HI & 5 & + \\
\hline $\mathrm{N} 27$ & Dea & $1,2,3,5,6,7$ & + \\
\hline Q51 & Dea & 3 & - \\
\hline K88 & Cbe & 7 & + \\
\hline R127 & MG-HI & $2,5,9$ & + \\
\hline K136 & $\mathrm{Cbm}$ & 7 & + \\
\hline K154 & Cbe & 5 & + \\
\hline N172 & Dea & 9 & + \\
\hline R173 & $3 D G$ & $2,4,5,7$ & + \\
\hline K234 & $\mathrm{Cbm}$ & 2 & + \\
\hline K237 & $\mathrm{Cbm} / \mathrm{Cbe}$ & $5,7,8,9,10$ & + \\
\hline R242 & $\mathrm{Cbe} / \mathrm{MG}-\mathrm{HI}$ & $4,5,7,8,9,10$ & + \\
\hline N246 & Dea & 5 & + \\
\hline Q264 & Dea & 1,2 & + \\
\hline N265 & Dea & $2,3,4,5,7$ & - \\
\hline N272 & Dea & 3 & - \\
\hline N278 & Dea & 1 & + \\
\hline N280 & Dea & 1 & + \\
\hline Q291 & Dea & 1,4 & + \\
\hline Q298 & Dea & 1 & + \\
\hline K306 & $\mathrm{Cbm}$ & $2,5,7$ & + \\
\hline N309 & Dea & $4,6,11$ & + \\
\hline K315 & $\mathrm{Hex} / \mathrm{Cbm}$ & $2,4,5,7$ & + \\
\hline N326 & Dea & $1,2,3,8,9$ & + \\
\hline Q360 & Dea & 3 & + \\
\hline K381 & $\mathrm{Cbm}$ & 2 & + \\
\hline K383 & Cbe & 2 & + \\
\hline K389 & $\mathrm{Cbm} / \mathrm{Cbe}$ & $4,5,9,11$ & + \\
\hline K392 & Cbe & 4 & + \\
\hline Q393 & Dea & 4 & + \\
\hline Q399 & Dea & 1,2 & + \\
\hline R413 & Cbe & $2,5,7$ & + \\
\hline N421 & Dea & 4 & + \\
\hline R437 & MG-HI & $2,4,5,7,9,11$ & + \\
\hline R442 & MG-HI/Cbe/Hex & $3,7,8,9$ & + \\
\hline Q443 & Dea & $3,6,8,9$ & - \\
\hline N444 & Dea & $3,7,8,9$ & + \\
\hline N463 & Dea & $5,6,7,8$ & - \\
\hline
\end{tabular}

${ }^{a}$ No modifications were identified from band 12 . The identified types of glycation are indicated as Hex: glycation with hexose, 3DG: 3-deoxyglucosone, Cbm: carboxymethyl, Cbe: carboxyethyl, MG-HI: methylglyoxal-derived hydroimidazolone, Dea: deamidation. Covered indicates whether or not the modified residue site is directly mapped by the MS/MS results.

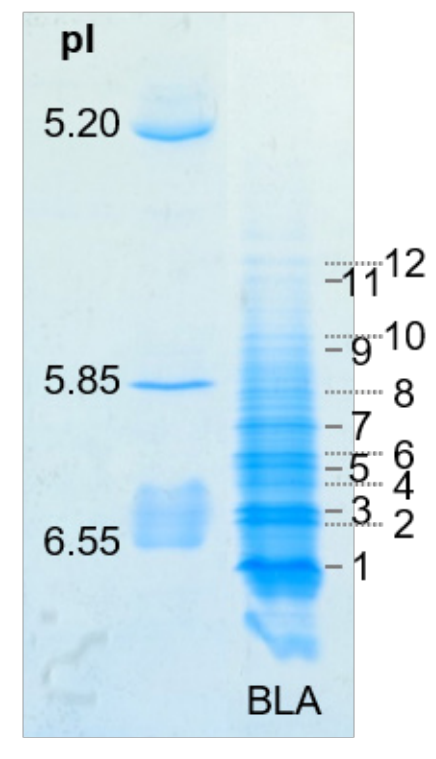

Figure 1: IEF of industrial BLA (Lane 2). Twelve bands were selected over the entire pl span for in-gel digestion by trypsin and Asp-N followed by LC-MS/MS identification of modified residues (see Table 1). Lane 1 is the pl marker.

binding were found to contain modifications and eight of these reacted positions were subjected to singleresidue substitution (Q9E, N172D, Q264E, N265D, Q360E, $\mathrm{K} 306 \mathrm{M}, \mathrm{K} 383 \mathrm{M}$ and $\mathrm{R} 437 \mathrm{~L}$ ) to assess the impact of the modifications on the performance of BLA.

\subsection{Physico-chemical and enzyme kinetic properties of BLA mutants}

The produced eight BLA single mutants were made at positions either near the catalytic site, in the substrate binding site or at the two SBSs. While deamidated positions were directly substituted $(\mathrm{Q} \rightarrow \mathrm{E}, \mathrm{N} \rightarrow \mathrm{D})$, the glycations of lysine or arginine were mimicked by replacement with methionine and leucine, respectively, to contain comparable side chains that are inert to reactions with reducing sugars. All purified BLA mutants migrated in SDS-PAGE as single bands of about $55 \mathrm{kDa}$ and for the majority $\mathrm{pI}$ decreased as expected by introduction of an acidic or removal of a basic side chain (Fig. 2). Surprisingly, however, BLA N172D and K306M essentially maintained wild-type pI, while pI of Q9E BLA decreased less than for the other $\mathrm{Q} \rightarrow \mathrm{E} / \mathrm{N} \rightarrow \mathrm{D}$ mutants (Fig. 2). It is noted that the pattern of protein forms of different isoelectric points for the major bands 1 through 7 (Fig. 1) do recur with similar relative intensities in the recombinant BLA wild-type and mutants produced in B. subtilis (Fig. 2). The conformational 


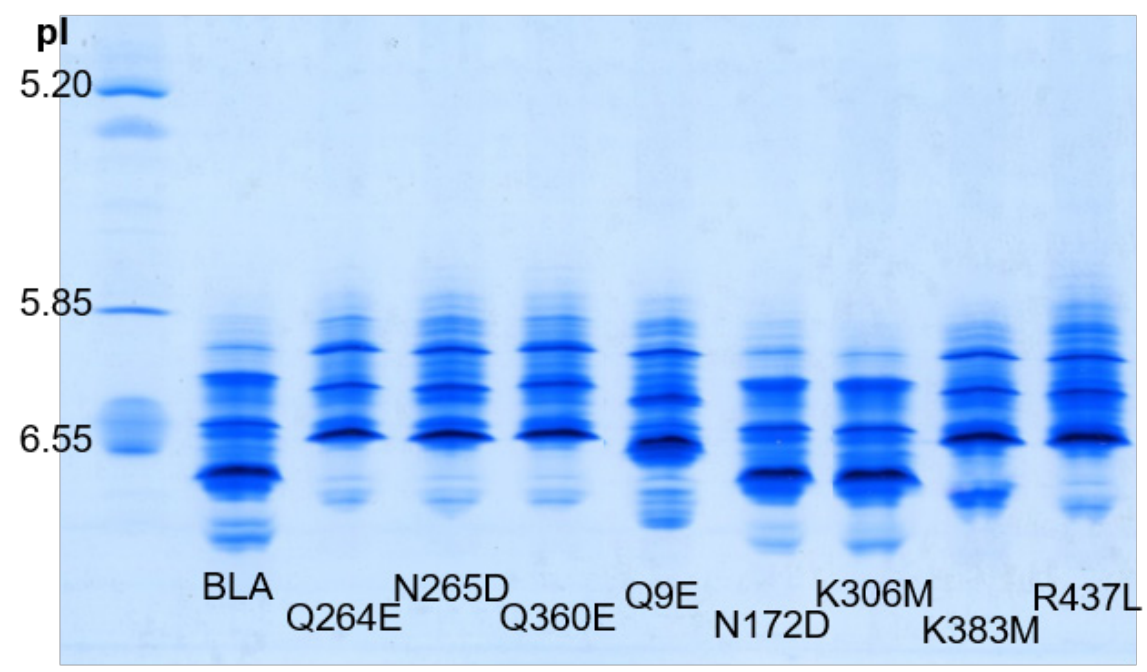

Figure 2: IEF of the eight BLA mutants and BLA wild-type produced in Bacillus subtilis.

Table 2: $T_{\max }$ values for the BLA wild-type and mutants determined by DSC.

\begin{tabular}{|c|c|c|c|c|c|c|c|c|c|}
\hline & WT & Q9E & N172D & Q264E & N265D & K306M & Q360E & K383M & R437L \\
\hline $\mathrm{T}_{\max }\left({ }^{\circ} \mathrm{C}\right)$ & 103.2 & 100.6 & 98.9 & 99.2 & 102.9 & 103.4 & 102.7 & 103.2 & 103.1 \\
\hline
\end{tabular}

integrity seemed barely affected by the mutations as DSC analysis confirmed the thermostability since the $\mathrm{T}_{\max }$ of BLA wild-type determined to $103.2^{\circ} \mathrm{C}$ was largely retained, although $\mathrm{T}_{\max }$ values of Q9E, N172D and Q264E decreased by $2.6,4.3$ and $4.0^{\circ} \mathrm{C}$, respectively (Table 2 ).

Some mutations caused up to almost 3-fold and in other cases no changes in the enzyme activity occurred. Thus while the kinetic parameters $\left(k_{\text {cat }}\right.$ and $\left.K_{\mathrm{M}}\right)$ for a maltoheptaose derivative and amylose of DP 440 were very similar to those of BLA wild-type, for N172D, K306M and K383M, Q264E and R437L significantly improved activity on both substrates essentially due to reduced $K_{\mathrm{M}}$ and increased $k_{\text {cat }}$, respectively (Table 3 ). Furthermore, Q360E showed 2-3 fold increase of both $k_{\text {cat }}$ and $K_{\mathrm{M}}$ on both substrates, while N265D slightly improved $k_{\text {cat }}$ and the Q9E mutation increased $K_{\mathrm{M}}$ on the oligosaccharide and reduced $k_{\text {cat }}$ on the polysaccharide (Table 3).

\subsection{Effect of mutations on wash performance of BLA}

Laundry wash performance was assayed at $40{ }^{\circ} \mathrm{C}$, a standard wash temperature in Europe, on cotton swatches with pink coloured starch using either a liquid detergent system at $\mathrm{pH} 8.5$ or a so-called powder detergent at $\mathrm{pH} 10$. The wash efficiency was determined spectrophotometrically by exposing the cotton swatch to light and measuring the reflected light (referred to as the remission) and given in delta remission units. The higher the value of delta remission the better is the removal of the coloured starch and thus the wash performance.

In liquid detergent at $\mathrm{pH} 8.5$ all eight BLA mutants showed superior wash performance compared to that of wild-type (Fig. 3A), N265D having 5-fold increased and the highest efficiency of all. The other mutants enhanced washing performance by $>1.5$ delta remission units (at 0.5 and $1.0 \mathrm{mg} / \mathrm{L}$ enzyme), considered a threshold for indicating a significant improvement. Q360E, however, only raised the value by about 1 delta remission unit over wild-type BLA. N265D also showed best wash performance in powder detergent at $\mathrm{pH} \mathrm{10,} \mathrm{where} \mathrm{as} \mathrm{well} \mathrm{the} \mathrm{K306M,}$ Q360E, Q264E and K383M mutants were significantly improved over wild-type BLA, while N172D and R437L performed similarly to and Q9E worse than BLA wild-type (Fig. 3B). 
Table 3: The kinetic parameters $k_{\text {cat }}, K_{\mathrm{M}}$ and $k_{\text {cat }} / K_{\mathrm{M}}$ for the BLA mutants and BLA determined at $30^{\circ} \mathrm{CpH} 7.0$ on the maltoheptaose derivative and amylose DP 440 substrates. $^{a}$

\begin{tabular}{|c|c|c|c|c|c|c|}
\hline & Maltohep & & & Amylose & & \\
\hline BLA & $k_{\text {cat }}\left(\mathbf{s}^{-1}\right)$ & $K_{M}(\mathrm{mM})$ & $k_{\text {cat }} / K_{\mathrm{M}}\left(\mathbf{s}^{-1} \mathrm{mM}^{-1}\right)$ & $k_{\text {cat }}\left(\mathbf{s}^{-1}\right)$ & $K_{\mathrm{M}}(\mathrm{mg} / \mathrm{mL})$ & $k_{\text {cat }} / K_{\mathrm{m}}\left(\mathrm{s}^{-1} \mathrm{mg}^{-1} \mathrm{~mL}\right)$ \\
\hline WT & $65 \pm 12$ & $0.011 \pm 0.003$ & $5922(100)$ & $200 \pm 8$ & $0.140 \pm 0.03$ & $1455(100)$ \\
\hline Q9E & $63 \pm 14$ & $0.027 \pm 0.008$ & $2394(40)$ & $117 \pm 12$ & $0.112 \pm 0.04$ & $1099(76)$ \\
\hline N172D & $70 \pm 9$ & $0.013 \pm 0.005$ & $5462(92)$ & $201 \pm 6$ & $0.129 \pm 0.01$ & $1555(107)$ \\
\hline Q264E & $60 \pm 5$ & $0.005 \pm 0.001$ & $13013(220)$ & $228 \pm 15$ & $0.089 \pm 0.02$ & $2632(180)$ \\
\hline N265D & $83 \pm 5$ & $0.011 \pm 0.002$ & $7277(123)$ & $232 \pm 28$ & $0.128 \pm 0.03$ & $1852(127)$ \\
\hline K306M & $70 \pm 4$ & $0.010 \pm 0.001$ & 7335 (124) & $213 \pm 38$ & $0.125 \pm 0.04$ & $1740(120)$ \\
\hline Q360E & $155 \pm 24$ & $0.026 \pm 0.005$ & $5996(101)$ & $416 \pm 17$ & $0.261 \pm 0.06$ & $1630(112)$ \\
\hline K383M & $69 \pm 10$ & $0.010 \pm 0.002$ & $7133(120)$ & $241 \pm 33$ & $0.139 \pm 0.02$ & $1743(120)$ \\
\hline R437L & $81 \pm 18$ & $0.010 \pm 0.003$ & $8153(138)$ & $307 \pm 67$ & $0.137 \pm 0.02$ & $2249(155)$ \\
\hline
\end{tabular}

${ }^{a} k_{\text {cat }} / K_{\mathrm{M}}$ values relative to wild-type are given in parenthesis.

A

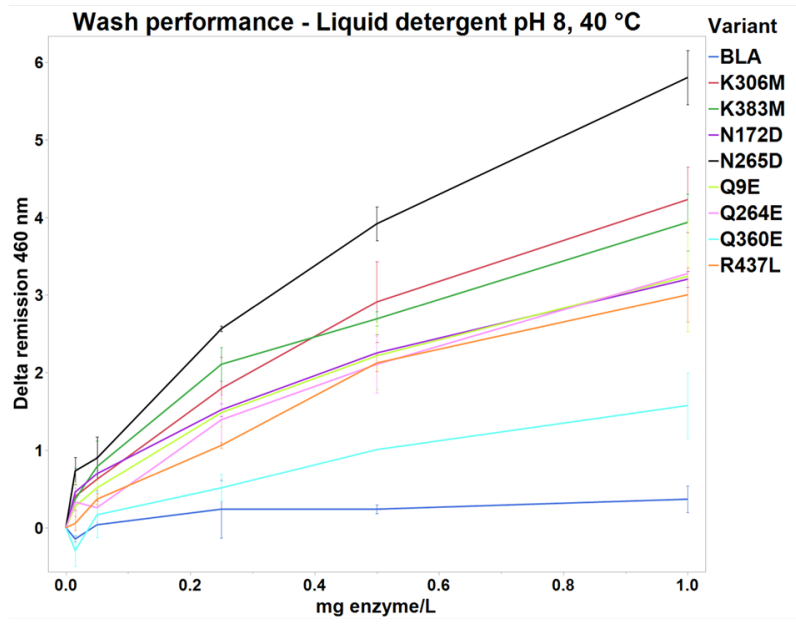

B

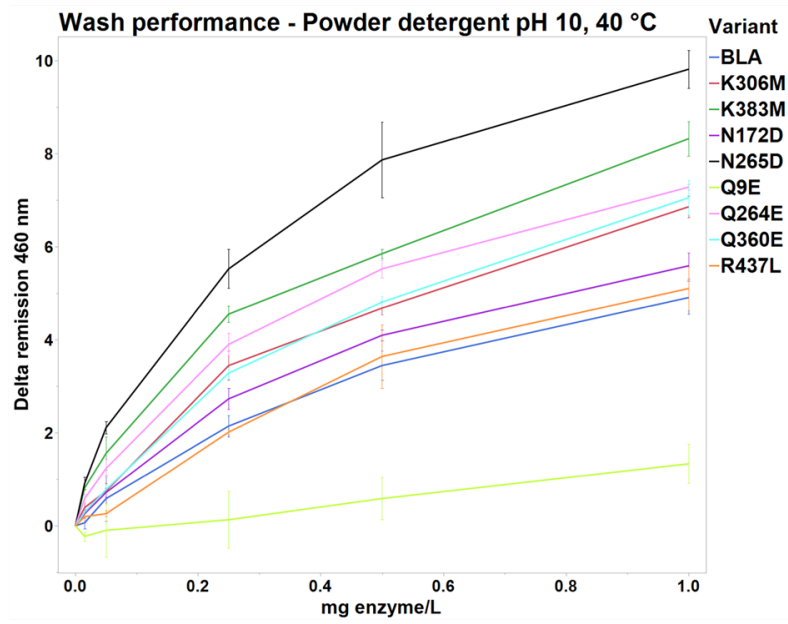

Figure 3: Wash performance of the BLA wild-type and mutants on rice starch cotton patches. (A) Wash performance in liquid detergent (pH 8.5). (B) Wash performance in powder detergent $(\mathrm{pH} 10.0)$. The bars show standard deviation.

\section{Discussion}

\subsection{Identification of deamidated and glycated residues in BLA}

In industrial-scale production of BLA, sucrose used as carbon source in B. licheniformis fermentation can get hydrolysed during heat-sterilisation [34] causing protein glycation by reaction with glucose and fructose. Lysine glycation and also deamidation of BLA were noticed previously to reduce stability and affect activity and substrate specificity [35-40]. In the present work altogether 40 asparagine, glutamine, lysine and arginine residues of BLA have been identified as modified during the fermentation, which resulted in multiple BLA protein forms of varying pI. As expected, generally the reacting side chains are exposed on the BLA surface, although a few less accessible, albeit still deamidated residues were situated near the active site. Twenty modified residues are marked at important sites on the BLA structural model (Fig. 4). Amongst these positions, R127, N172, R173, K237 and N272 are located at the interface between domains A and $B$ that harbours the $\mathrm{Ca}^{2+}-\mathrm{Na}^{+}-\mathrm{Ca}^{2+}$ triad proposed to be vital for BLA thermostability $[1,10,12,13,41]$. The residues N172 


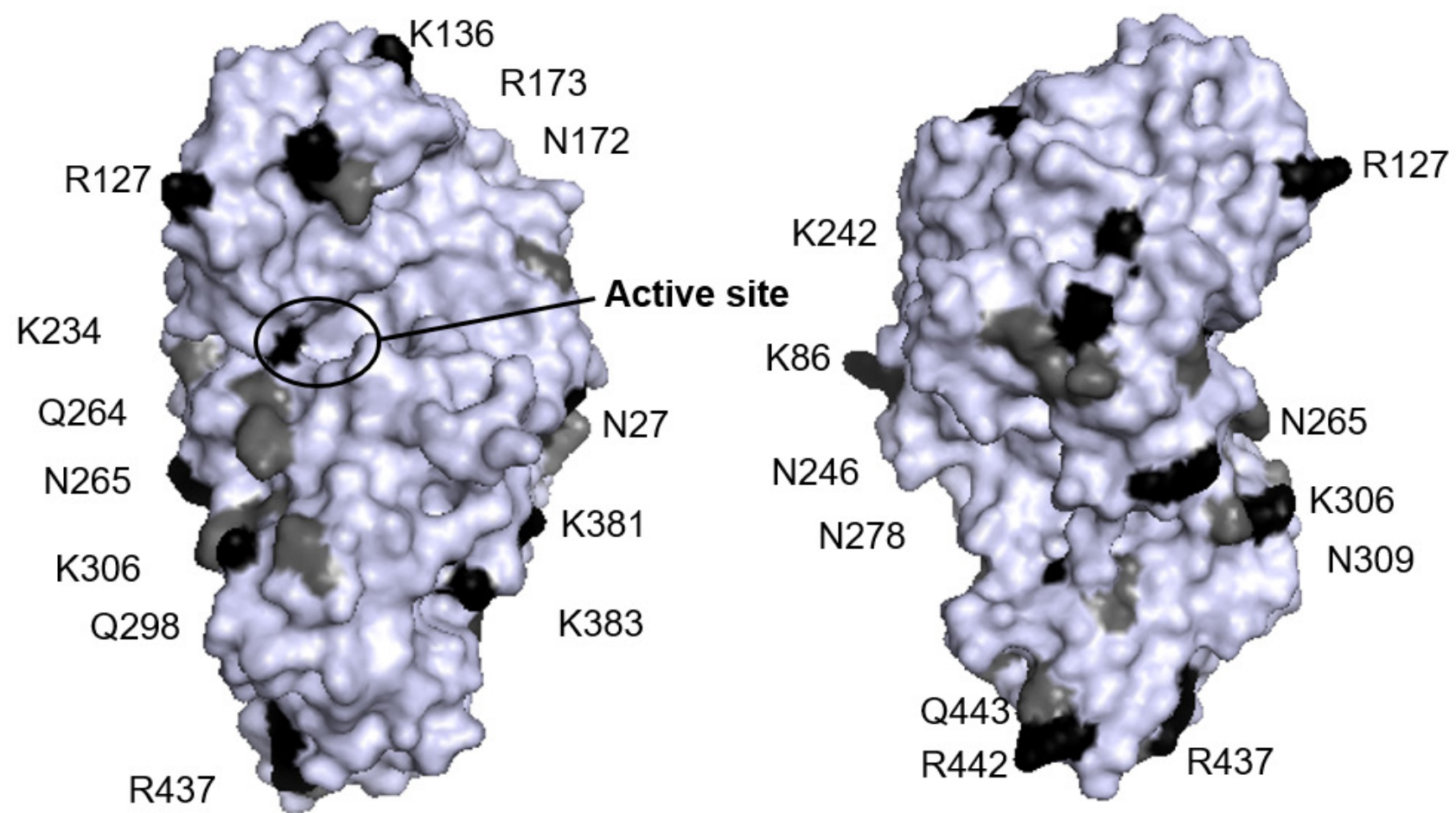

Figure 4: Surface representation of BLA (PDB code: 1BLI) indicating 20 of the identified deamidated Asn and Gln residues (in grey) and glycated Lys and Arg residues (in black). PyMOL was used for molecular rendering (The PyMOL Molecular Graphics System, version 1.3, Schrödinger, LCC).

and R173 from domain B probably belong to an extended substrate binding site. The precise role of these residues has not been elucidated although the "170-loop" in BLA is important in substrate interactions involving D164, W165 and F167 [1]. Additionally, deamidation of Q9, N326 and Q360 situated in the substrate binding cleft as well as Q264 and the glycated $\mathrm{K} 234$, contributing to subsites +3 and +1 , respectively, may affect enzyme activity [1,7,10]. Moreover, while the mascot score $[42,43]$ for N265 was low and also the deamidation product D265 was not identified by MS/ MS, E264, the deamidated Q264, was robustly identified and found in the most prominent BLA form seen in IEF (band 1, Fig. 1; Table 1). However, since $K_{\mathrm{M}}$ values of the N265D BLA mutant for maltoheptaose and amylose were the same as for BLA wild-type and $k_{\text {cat }}$ increased modestly by $15-20 \%$, the deamidation of N265 situated adjacent to Q264, is not likely to influence activity. By contrast, the BLA Q264E mutation improved substrate affinity by 2-3 fold for both the oligosaccharide and polysaccharide substrates.

Sequence alignment and structural analysis suggest that BLA has counterparts to two SBSs, documented in the structure of the close homologues BHA and Bacillus paralicheniformis $\alpha$-amylase containing W342, P432 and D430 bound to maltose, R437 and W467 binding glucose and L318, K319 and Y358 binding different maltooligosaccharides [14,44]. Indeed, BLA R437 is glycated and the structurally adjacent N463 is deamidated. K383 situated in the vicinity of W342 is also glycated. The modifications likely stem from the ability of the SBSs to bind carbohydrates thus promoting glycation of the arginine and lysine residues, which in turn may interfere with substrate binding functions of the SBSs. Finally, glycation occurred of K306 situated in an area extending beyond subsite +3 of the substrate binding cleft. While BLA R437L showed about 50\% elevated activity towards the maltoheptaose and amylose substrates, the mutants K306M beyond substrate binding subsite +3 and K383M in the vicinity of an SBS, respectively, had slightly elevated activity on both substrates suggesting that glycation at these side chains reduces the wild-type BLA activity.

\subsection{Properties of the individual BLA mutants}

Q264E at subsite +3 showed the best catalytic efficiency corresponding to 2-3 fold larger than wild-type BLA due to higher substrate affinity and also clearly improved 


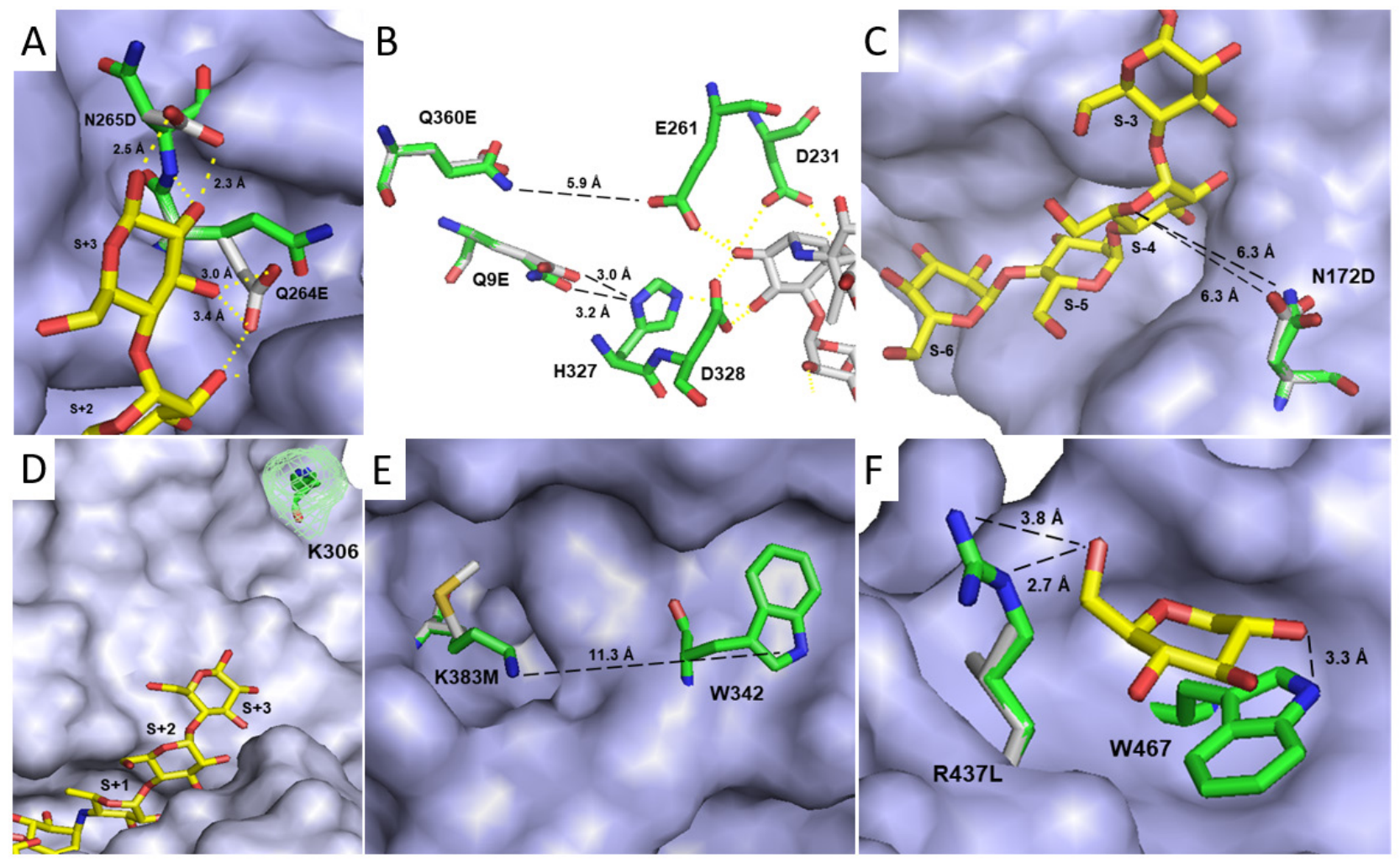

Figure 5: Close-up views of the mutated amino acid residues in the crystal structure of BLA in complex with acarbose (unpublished structure of BLA in complex acarbose, courtesy of Novozymes). (A) Possible substrate interactions with Q264 and N265 (in green) as well as the Glu and Asp mutant residues (in grey). Subsites +2 and +3 are labelled as $S+2$ and $S+3$. (B) The active site showing the three catalytic site residues D231, E261 and D328 along with Q9, Q360 and H327. The original BLA residues (in green) and the two Glu mutant residues (in grey) are shown. The nitrogen between the two non-reducing end rings in acarbose is shown in blue. (C) BLA in complex with acarbose at the substrate binding cleft showing the residue N172 (in green) and the Asp mutant residue (in grey). The subsites of the binding site are numbered and indicated by S. (D) Acarbose in the active site and K306 shown in a putative extended substrate binding region. Substrate binding subsites are numbered and indicated by S. (E) K383 and W342 at one of the SBS. (F) R437 and W467 at another SBS with bound glucose. The position of R437 is assessed by modelling guided by the position of W439 in BHA solved with bound glucose [14]. (The PyMOL Molecular Graphics System, Version 1.3, Schrödinger, LCC).

the wash efficiency at both $\mathrm{pH} 8.5$ and $\mathrm{pH}$ 10. Probably the glutamic acid forms a stronger hydrogen bond with substrate than glutamine in BLA wild-type. Indeed, in the acarbose complex of a different BLA variant (unpublished) the side chain of Q264 points away from the inhibitor, whereas the flexible side chain of Q264E can form hydrogen bonds with glucose residues at subsites +2 and +3 (Fig. 5A). Even though mutation of the adjacent N265 to N265D caused only marginally improved $k_{\text {cat }}$ and catalytic efficiency towards maltoheptaose and amylose, N265D was the best of all mutants in wash performance. N265 is within hydrogen bonding distance of acarbose at subsite +3 in the BLA complex (Fig. 5A) and the exceptionally large 5 -fold increase in wash performance suggests reinforced interaction of N265D with the rice starch patch on the textile perhaps also facilitated by favourable binding of BLA N265D to the fabric.
Q9E, located behind the highly conserved H327 that is involved in transition state stabilisation at subsite -1 (Fig. 5B), had lowest catalytic efficiency for both maltoheptaose and amylose of all mutants, the loss of activity being largest on the oligosaccharide. The Q9E mutant is able to interact electrostatically with H327 and thus to weaken transition state stabilisation, possibly explaining the substantial decreases in activity by 60 and $24 \%$. Still wash performance of Q9E was improved in liquid detergent at $\mathrm{pH} 8.5$, but was in powder detergent wash at $\mathrm{pH} 10$ reduced importantly compared to wild-type BLA and the seven other mutants. This $\mathrm{pH}$ dependency perhaps reflects that Q9E perturbs $\mathrm{p} K_{\mathrm{a}}$ of amino acid side chains at or near the catalytic site [40] although it cannot be excluded that the poor wash performance stems from loss of in-wash stability caused by one or more detergent components [39]. Q360 is situated very close to Q9 and 5.9 
Å from the catalytic acid/base E261. The Q360E mutation may have shifted the BLA pH activity profile. Still, the catalytic efficiency on maltoheptaose and amylose was maintained as a $>2$-fold increase in $k_{\text {cat }}$ was accompanied by a similar increase in $K_{\mathrm{M}}$ and the wash performance of Q360E was slightly improved in powder detergent but unchanged in liquid detergent. The N172D belonging to domain $B$ and situated in the near vicinity of the substrate binding cleft about 5 Å from the bound acarbose (Fig. 5C) showed a modest improvement only in liquid detergent.

K306M at a putative binding area extending beyond subsite +3 (Fig. 5D) maintained kinetic parameters for amylose and improved the wash performance. K383M close to W342 at a proposed SBS (Fig. 5E) showed marginal effect on kinetic parameters, but was clearly superior to wild-type in wash performance in both detergent systems and possibly weakened the interaction with substrate on the fabric. Noticeably, this is a mutation for which a possible loss of glycation of K383 during BLA production can allow substrate interaction with the SBS. R437 and W467 are at another SBS, found on the surface of domain C, and R437 hydrogen bonds with 0-6 of glucose modelled (Fig. 5F) as guided by glucose binding to W439 in BHA [14]. R437L improved $k_{\text {cat }}$ and catalytic efficiency towards amylose DP400 along with improved wash performance in liquid detergent in agreement with SBSs playing roles in activity.

\section{Conclusion}

During enzyme production by industrial fermentation deamidation and glycation generated multiple forms of BLA having different $\mathrm{pI}$ values. While the various modified enzyme forms were not characterized individually, a large number of chemically modified positions could be identified by mass spectrometry, of which some are situated at or near sites known to be important for enzyme stability, activity and substrate binding. Remarkably, single-site mutants of BLA mimicking some of these chemical modifications had improved textile wash performance and, except for a few, mostly influenced activity and substrate binding positively. Substitution in K306M, K383M and R437L of residues susceptible to glycation at a distance from the active site, including two SBSs, thus modestly improved enzyme activity and enhanced the wash performance, especially in liquid detergent. Among five mutants mimicking deamidation Q264E and N265D, both probably engaged at subsite +3 , showed the highest activity towards substrates in solution and remarkably improved wash performance removing rice starch on fabric.

Acknowledgments: Anne Blicher (DTU) is thanked for amino acid analysis. This project was funded by the Danish Agency for Science Technology and Innovation (now Innovation Fund Denmark) by an industrial PhD fellowship. We are grateful to the late Susanne Jacobsen for a very stimulating collaboration.

Conflict of interest: Carsten Andersen and Svend G. Kaasgaard are employees of Novozymes, Connie Pontoppidan and Carsten P. Sönksen were employees of Novozymes when this work was conducted. Birte Svensson has no conflict of interest to declare.

\section{References}

[1] Machius M., Declerck N., Huber R., Wiegand G., Activation of Bacillus licheniformis $\alpha$-amylase though disorder à order transition of the substrate binding site mediated by a calciumsodium-calcium metal triad. Structure 1998, 6, 281-292. https://doi.org/10.1016/S0969-2126(98)00032-X

[2] Vihinen M., Mantsala P., Microbial amylolytic enzymes. Crit. Rev. Biochem. Mol. Biol. 1989, 24, 329-418. https://doi. org/10.3109/10409238909082556

[3] MacGregor E.A., Janecek S., Svensson B., Relationship of sequence and structure to specificity in the a-amylase family. Biochim. Biophys. Acta 2001, 1546, 1-20. https://doi. org/10.1016/S0167-4838(00)00302-2

[4] Lombard V., Golaconda Ramulu H., Drula E., Coutinho P.M., Henrissat B., The carbohydrate-active enzymes database (CAZy) in 2013. Nucleic Acids Res. 2014, 42, D490-D495. https://doi.org/10.1093/nar/gkt1178

[5] de Souza P.M., Magalhaes P.D.E., Application of microbial $\alpha$-amylase in industry - a review. Braz. J. Microbiol. 2010, 41, 850-861. https://doi.org/10.1590/S1517-83822010000400004

[6] Kirk O., Borchert T.V., Fuglsang C.C., Industrial enzyme applications. Curr. Opin. Biotechnol. 2002, 13, 345-351. https://doi.org/10.1016/S0958-1669(02)00328-2

[7] Nielsen J.E., Borchert T.V., Protein enginineering of bacterial $\alpha$-amylases. Biochim. Biophys. Acta 2000, 1543, 253-274. https://doi.org/10.1016S0167-4838(00)00240-5

[8] Stam M.R., Danchin E.G.J., Rancurel C., Coutinho P.M., Henrissat B., Dividing the large glycoside hydrolase family 13 into subfamilies: towards improved functional annotations of $\alpha$-amylase-related proteins. Protein Eng. Des. Sel. 2006, 19, 555-562. https://doi.org/10.1093/protein/gzl044

[9] Yuuki T., Nomura T., Tezuka H., Tsuboi A., Yamagata H., Tsukagoshi N., Udaka S., Complete nucleotide sequence of a gene coding for heat- and $\mathrm{pH}$-stable $\alpha$-amylase of Bacillus licheniformis: comparison of the amino acid sequences of three bacterial liquefying $\alpha$-amylases deduced from the DNA sequences. J. Biochem. 1985, 98, 1147-1156. https://doi. org/10.1093/oxfordjournals.jbchem.a135381 
[10] Machius M., Wiegand G., Huber R., Crystal structure of calciumdepleted Bacillus licheniformis $\alpha$-amylase at $2.2 \AA$ resolution. J. Mol. Biol. 1995, 246, 545-559. https://doi.org/10.1006/ jmbi.1994.0106

[11] Kandra L., Gyémánt G., Remenyik J., Hovánszki G., Lipták A., Action pattern and subsite mapping of Bacillus licheniformis $\alpha$-amylase (BLA) with modified maltooligosaccharide substrates. FEBS Lett. 2002, 518, 79-82. https://doi. org/10.1016/S0014-5793(02)02649-2

[12] Declerck N., Machius M., Wiegand G., Huber R., Gaillardin C., Probing structural determinants specifying high thermostability in Bacillus licheniformis $\alpha$-amylase. J. Mol. Biol. 2000, 301, 1041-1057. https://doi.org/10.1006/ jmbi.2000.4025

[13] Declerck N., Machius M., Joyet P., Wiegand G., Huber R., Gaillardin C., Hyperthermostabilization of Bacillus licheniformis $\alpha$-amylase and modulation of its stability over a $50{ }^{\circ} \mathrm{C}$ temperature range. Protein Eng. 2003, 16, 287-294. https://doi.org/10.1093/proeng/gzg032

[14] Lyhne-Iversen L., Hobley T.J., Kaasgaard S.G., Harris P., Structure of Bacillus halmapalus $\alpha$-amylase crystallized with and without the substrate analogue acarbose and maltose. Acta Crystallogr. Sect. F Struct. Biol. Cryst. Commun. 2006, 62, 849-854. https://doi.org/10.1107/S174430910603096X

[15] Cuyvers S., Dornez E., Delcour J.A., Courtin C.M., Occurrence and functional significance of secondary carbohydrate binding sites in glycoside hydrolases. Crit. Rev. Biotechnol. 2012, 32, 93-107. https://doi.org/10.3109/07388551.2011.561537

[16] Nielsen M.M., Seo E.S., Dilokpimol A., Andersen J., Abou Hachem M., Naested H., Willemoës M., Bozonnet S., Kandra L., Gyémánt G., Haser R., Aghajari N., Svensson B., Roles of multiple surface sites, long substrate cinding clefts, and carbohydrate binding modules in the action of amylolytic enzymes on polysaccharide substrates. Biocatal. Biotransform. 2008, 26, 59-67. https://doi. org/10.1080/10242420701789528

[17] Cockburn D., Svensson B., Surface binding sites in carbohydrate active enzymes: an emerging picture of structural and functional diversity, pp 204-221. In: Rauter P. \& Lindhorst T. (eds) Carbohydrate Chemistry vol. 39, Royal Society of Chemistry, Cambridge, United Kingdom, 2013. https://doi. org/10.1039/9781849737173-00204

[18] Cockburn D., Nielsen M.M., Christiansen C., Andersen J.M., Rannes J.B., Blennow A., Svensson B., Surface binding sites in amylase have distinct roles in recognition of starch structure motifs and degradation. Int. J. Biol. Macromol. 2015, 75, 338-345. https://doi.org/10.1016/j.ijbiomac.2015.01.054

[19] Jenkins N., Murphy L., Tyther R., Post-tanslational modification of recombinant proteins: significance for biopharmaceuticals. Mol. Biotechnol. 2008, 39, 113-118. https://doi.org/10.1007/ s12033-008-9049-4

[20] Manning M., Chou D., Murphy B., Payne R., Katayama D., Stability of protein pharmaceuticals: an update. Pharmaceut. Res. 2010, 27, 544-557. https://doi.org/10.1007/s11095-0090045-6

[21] Baynes J.W., Watkins N.G., Fisher C.I., Hull C.J., Patrick J.S., Ahmed M.U., Dunn J.A., Thorpe S.R., The Amadori product on protein: structure and reactions. Progr. Clin. Biol. Res. 1989, 304, 43-67.
[22] Brownlee M., Cerami A., Vlassara H., Advanced glycosylation end products in tissue and the biochemical basis of diabetic complications. New England J. Med. 1988, 318, 1315-1321. https://doi.org/10.1056/NEJM198805193182007

[23] Ames J.M., Mass spectrometry to detect the site specificity of advanced glycation/lipoxidation end-product formation on protein: some challenges and solutions. Biochem. Soc. Trans. 2008, 36, 1051-1054. https://doi.org/10.1042/BST0361051

[24] Barnaby O.S., Cerny R.L., Clarke W., Hage D.S., Comparison of modification sites formed on human serum albumin at various stages of glycation. Clin. Chim. Acta 2011, 412, 277-285. https://doi.org/10.1016/j.cca.2010.10.018

[25] Kislinger T., Humeny A., Pischetsrieder M., Analysis of protein glycation products by matrix-assisted laser desorption ionization time-of-flight mass spectrometry. Curr. Med. Chem. 2004, 11, 2185-2193. https://doi. org/10.2174/0929867043364649

[26] Kislinger T., Humeny A., Peich C.C., Becker C.M., Pischetsrieder M., Analysis of protein glycation products by MALDI-TOF/MS. Ann. New York Acad. Sci. 2005, 1043, 249-259. https://doi. org/10.1196/annals.1333.030

[27] Deng W.P., Nickoloff J.A., Site-directed mutagenesis of virtually any plasmid by eliminating a unique site. Anal. Biochem. 1992, 200, 81-88. https://doi.org/10.1016/0003-2697(92)90280-k

[28] Barkholt V., Jensen A.L., Amino acid analysis: determination of cysteine plus half-cystine in proteins after hydrochloric acid hydrolysis with a disulfide compound as additive. Anal. Biochem. 1989, 177, 318-322. https://doi.org/10.1016/00032697(89)90059-6

[29] van Wandelen C., Cohen S.A., Using quarternary high performance liquid chromatography eluent systems for separating 6-aminoquinolyl- $N$-hydroxysuccinimidyl carbamatederivatized amino acid mixtures. J. Chromatogr. A 1997, 763, 11. https://doi.org/10.1016/S0021-9673(96)00891-6

[30] Gaza-Bulseco G., Li B.Q., Bulseco A., Liu H.C., Method to differentiate Asn deamidation that occurred prior to and during sample preparation of a monoclonal antibody. Anal. Chem. 2008, 80, 9491-9498. https://doi.org/10.1021/ac801617u

[31] Li X.J., Cournoyer J.J., Lin C., O'Connor P.B., Use of 0-18 labels to monitor deamidation during protein and peptide sample processing. J. Am. Soc. Mass. Spectrom. 2008, 19, 855-864. https://doi.org/10.1016/j.jasms.2008.02.011

[32] Bozonnet S., Jensen M.T., Nielsen M.M., Aghajari N., Jensen M.H., Kramhøft B., Willemoës M., Tranier S., Haser R., Svensson B., The "pair of sugar tongs" site on the non-catalytic domain C of barley a-amylase participates in substrate binding and activity. FEBS J. 2007, 274, 5055-5067. https://doi.org/10.1111/ j.1742-4658.2007.06024.x

[33] Mori H., Bak-Jensen K.S., Gottschalk T.E., Motawia S.M., Damager I., Møller B.L., Svensson B., Modulation of substrate binding mode by mutation of Met298 and Cys95 in barley a-amylase. Eur. J. Biochem. 2001, 268, 6545-6558. https://doi. org/10.1046/j.0014-2956.2001.02609.x

[34] Petersen K.K., Hansen J., Krogstrup P., Significance of different carbon sources and sterilization methods on callus induction and plant regeneration of Miscanthus x ogiformis Honda “Gigantus”. Plant Cell Tissue Organ Cult. 1999, 58, 189-197. https://doi.org/10.1023/A:1006348615717

[35] Habibi A.E., Khajeh K., Nemat-Gorgani M., Chemical modification of lysine residues in Bacillus licheniformis 
$\alpha$-amylase: conversion of an endo- to an exo-type enzyme. J. Biochem. Mol. Biol. 2004, 37, 642-647.

[36] Khajeh K., Naderi-Manesh H., Ranjbar B., Moosavi-Movahedi A.A., Nemat-Gorgani M., Chemical modification of lysine residues in Bacillus $\alpha$-amylase: effect on activity and stability. Enzyme Microb. Technol. 2001, 28, 543-549. https://doi. org/10.1016/s0141-0229(01)00296-4

[37] Khajeh K., Ranjbar B., Naderi-Manesh H., Habibi A.E., NematGorgani M., Chemical modification of bacterial $\alpha$-amylases: changes in tertiary structures and the effect of additional calcium. Biochim. Biophys. Acta 2001, 1548, 229-237. https:// doi.org/10.1016/S0167-4838(01)00236-9

[38] Tomazic S.J., Klibanov A.M., Why is one Bacillus $\alpha$-amylase more resistant against irreversible thermoinactivation than another. J. Biol. Chem. 1988, 263, 3092-3096. https://doi. org/10.1016/S0021-9258(18)69039-8

[39] Tomazic S.J., Klibanov A.M., Mechanisms of irrevesibel inactivation of Bacillus $\alpha$-amylases. J. Biol. Chem. 1988, 263, 3086-3091. https://doi.org/10.1016/S0021-9258(18)69038-6

[40] Nielsen J.E., Borchert T.V., Vriend G., The determinants of $\alpha$-amylase pH activity profiles. Protein Eng. 2001, 14, 505-512. https://doi.org/10.1093/protein/14.7.505

[41] Machius M., Declerck N., Huber R., Wiegand G., Kinetic stabilization of Bacillus licheniformis $\alpha$-amylase through insertion of hydrophobic residues at the surface. J. Biol. Chem. 2003, 278, 11546-11553. https://doi.org/10.1074/jbc. M212618200

[42] Perkins D.N., Pappin D.J., Creasy D.M., Cottrell J.S., Probabilitybased protein identification by searching sequence databases using mass spectrometry data. Electrophoresis 1999, 20, 3551-3567. https://doi.org/10.1002/(SICI)15222683(19991201)20:18\%3C3551::AID-ELPS3551\%3E3.0.CO;2-2

[43] Koenig T., Menze B.H., Kirchner M., Monigatti F., Parker K.C., Patterson T., Steen J.J., Hamprecht F.A., Steen H., Robust prediction of the MASCOT score for an improved quality assessment in mass spectrometric proteomics. J. Proteome Res. 2008, 7, 3708-3717. https://doi.org/10.1021/pr700859x

[44] Bozic N., Rozeboom H.J., Loncar N., Slavic M.S., Janssen D.B., Vujcic Z., Characterization of the starch surface binding site on Bacillus paralicheniformic $\alpha$-amylase. Int. J. Biol. Macromol. 2020, 165, 1529-1539. https://doi.org/10.1016/j. ijbiomac.2020.10.025 